\title{
Influence of Cutting Fluid Application Frequency in Micromilling Cutting Forces
}

\author{
De Oliveira, D., Gomes, M. G., Dos Santos, A. G. and Da Silva, M. B.
}

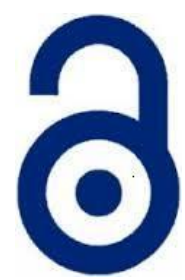

Received: 15 April 2021

Accepted: 29 April 2021

Published: 15 July 2021

Publisher: Deer Hill Publications

(C) 2021 The Author(s)

Creative Commons: CC BY 4.0

\begin{abstract}
Micromachining allows the production of parts and components on a micro scale with high precision and has become a key process to meet the growing demand for micro parts and micro components. To meet the quality requirements of the generated surfaces and reduce the cutting forces, strategies have been analysed, such as the use of the cutting fluid. Therefore, this research aimed to verify the effect of the frequency of the use of cutting fluid during the micromilling of the Inconel 718 alloy. For this purpose, an ultra-refined cemented carbide micro end mill coated with (Al, Ti) $\mathrm{N}$ and $400 \mu \mathrm{m}$ in diameter was used. A spindle speed of $20,000 \mathrm{rpm}$, a cutting speed of $13.8 \mathrm{~m} / \mathrm{min}$, a feed per tooth of $5 \mu \mathrm{m} /$ tooth and an axial depth of cut of $40 \mu \mathrm{m}$ were used as cutting parameters. Two frequencies of application of the cutting fluid were evaluated, corresponding to the flow rate of 40.7 and $270.0 \mathrm{ml} / \mathrm{h}$, in addition to the dry test. To measure the cutting forces, a Kistler dynamometer with operating range of $-5 \mathrm{kN}$ to $+10 \mathrm{kN}$ was used. In addition, the process simulation was performed using the AdvantEdge software by ThirdWave Systems. The results showed that the higher flow of the cutting fluid provided lower cutting forces and that, in dry machining, the cutting force increased significantly during the machining of a slot.
\end{abstract}

Keywords: Micromilling, Inconel 718, Cutting fluid, Cutting forces.

\section{INTRODUCTION}

Researches in microfabrication processes are experiencing a rapid evolution due to the growing demand for microproducts with possible applications in optical, mechanical, electrical, medical and biochemical devices [1]. In this scenario, the micro machining process is an important technology to provide micro parts with the required precision [2]. According to Saha et al. [3], micromachining allows the production of micro components with complex geometries, by removing material in the form of micro-chips and using a micro-tool with sharp edges. It is noteworthy that one of the characteristics that defines this process is related to the size of the tool. As an example, in micro milling, as exposed by Saha et al. [4], the diameter of the micro-cutter usually ranges from 0.01 to $1.0 \mathrm{~mm}$.

Micromachining has particularities that differentiate it from the conventional machining process due to the size effect. An important difference between the two processes is that, in micro machining, the undeformed chip thickness has a size comparable to the cutting-edge radius, exerting a strong influence on the chip formation mechanism [5]. Thus, there is a minimum uncut chip thickness for chip formation and this varies between 0.25 and 0.33 of the tool edge radii [6]. In addition, considering that the reductions that occur in the micro-machining process, such as in the tool size and cutting parameters, do not occur with the workpiece grains, the chip formation can therefore occur through the shearing of a single or a few grains $[7,8]$.

Due to the presence of the size effect in the micromachining processes, the reduction of the undeformed chip thickness does not have the same effect on the cutting forces when compared with conventional processes. In this case, the influence of the thickness on the forces is uncertain, while the force is high due to the increase in the chip cross-section, it is reduced since in this condition the effective exit angle of the tool becomes more positive, which decreases the occurrence of ploughing, and consequently, decreases the value of ploughing force [8].

The machining force, as well as its components, are important output variables to be studied both in machining processes on a macro scale, as well as in micromachining, as it estimates the power required for cutting, as well as

De Oliveira, D. 凶, Gomes, M.G., Dos Santos, A. G. and Da Silva, M.B.

Department of Mechanical Engineering,

Faculty of Technology,

University of Brasilia, Brazil.

E-mail: oliveira.deborah@unb.br

Reference: De Oliveira et al. (2021) Influence of Cutting Fluid Application Frequency in Micromilling Cutting Forces. International Journal of Engineering Materials and Manufacture, 6(3), 195-201. 
the forces that will act on the elements of the machine-tool. Besides, they directly affect the ability to obtain tight tolerances, cutting temperature, and tool wear [9].

The machining force has three basic components that act on the cutting edge: cutting force, feed force, and passive force [10]. In addition to these components, in the micromilling process, there is the presence of the ploughing force. This force will be very present in this process due to the size effect. This is a deformation force that acts at the tip of the cutting tool and at the interface of the chip tool, being responsible for the significant increase in the specific cutting energy [11].

One way to reduce the forces present in the cut is to use cutting fluids, thus guaranteeing less tool wear and higher quality of machined surfaces [12]. According to De Oliveira et. al [13] the cutting fluid must be applied at an appropriate rate, to ensure the homogeneous quality of the machined surface. In this work, the variation of the fluid application rate in the Inconel 718 micromilling was investigated, and it was observed that by using the highest fluid application rate (200 pulses per minute) it was possible to guarantee its presence on the entire surface of the slot, thus improving its surface finish.

Ziberov et al. [14] when performing the micromilling of the Ti-6Al-4V alloy, observed that the application of cutting fluid improves the quality of the machined surfaces, by reducing the wear of the cutting tool. In addition, they noted that the presence of the fluid influenced the size of the burrs formed. Demonstrating the great importance of using the cutting fluid in micromachining operations.

In view of this, the present work was developed with the aim of evaluating the influence of the frequency of application of the cutting fluid in the micromilling process of the nickel alloy Inconel 718.

\section{MATERIALS AND METHODS}

\subsection{Workpiece Material}

The workpiece material was the refractory nickel alloy Inconel 718, its austenitic microstructure can be observed in Figure 1. This alloy has high tensile strength, good chemical resistance, and the ability to operate continuously at high temperatures [15], Table 1 contain some of the material properties and Table 2 its chemical composition. The workpieces were machined to blocks of $15 \mathrm{~mm}$ X $20 \mathrm{~mm}$ X $15 \mathrm{~mm}$.

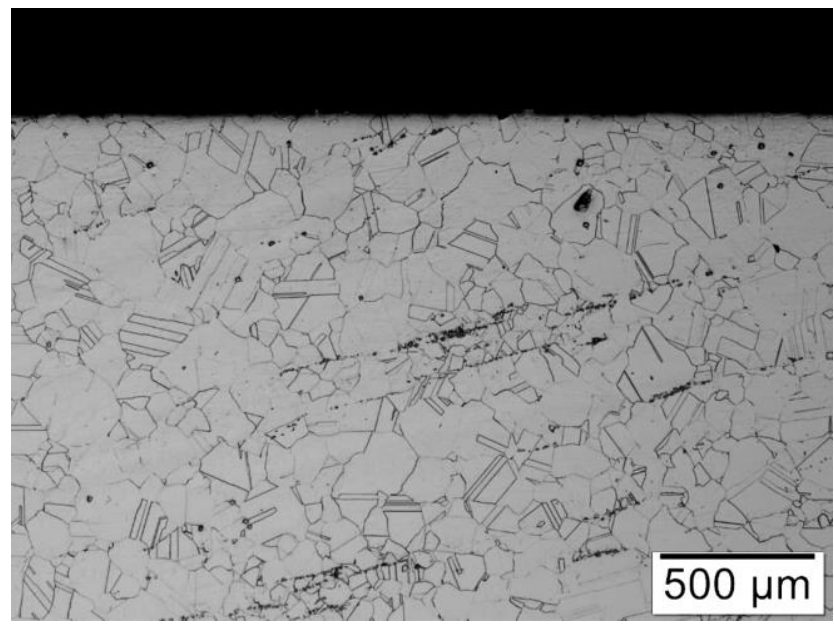

Figure 1: Inconel 718 microstructure [16]

Table 1: Mechanical properties of Inconel 718 [17]

\begin{tabular}{ccccccc}
\hline $\begin{array}{c}\text { Tensile } \\
\text { strength } \\
(\mathrm{MPa})\end{array}$ & $\begin{array}{c}\text { Yield } \\
\text { strength } \\
(\mathrm{MPa})\end{array}$ & $\begin{array}{c}\text { Young's } \\
\text { Modulus } \\
(\mathrm{GPa})\end{array}$ & $\begin{array}{c}\text { Hardness } \\
(\mathrm{HRc})\end{array}$ & $\begin{array}{c}\text { Room Temp } \\
\text { Density } \\
\left(\mathrm{g} / \mathrm{cm}^{3}\right)\end{array}$ & $\begin{array}{c}\text { Melting } \\
\text { Range }\left({ }^{\circ} \mathrm{C}\right)\end{array}$ & $\begin{array}{c}\text { Thermal } \\
\text { Conductivity } \\
(\mathrm{W} / \mathrm{mk})\end{array}$ \\
\hline 1275 & 1034 & 200 & 40 & 8.22 & $1260-1336$ & 11.4 \\
\hline
\end{tabular}

Table 2: Chemical composition of Inconel 718 [17]

\begin{tabular}{cccccccccc}
\hline Element & $\mathrm{C}$ & $\mathrm{Al}$ & $\mathrm{Ti}$ & $\mathrm{Cr}$ & $\mathrm{Fe}$ & $\mathrm{Ni}$ & $\mathrm{Nb}$ & $\mathrm{Mo}$ \\
\hline Percentage & 0.04 & 0.50 & 0.90 & 19.00 & 18.50 & 50.66 & 5.10 & 5.30 \\
\hline
\end{tabular}




\subsection{Micro Cutting Tools and Machine Tool}

The tool used in this work is a ultra-refined cemented carbide micro end mill (MS2MSD0040) coated with ( $\mathrm{Al}, \mathrm{Ti}) \mathrm{N}$, $400 \mu \mathrm{m}$ diameter, 2 flutes, manufactured by Mitsubishi. The geometry of the tool is shown in Figure 2, with some dimensions in millimetres.

The machine-tool was the Mini-mill / GX CNC, manufactured by Minitech Machinery Corporation®. It has a maximum spindle speed of $60000 \mathrm{rpm}, 4$ axes with position resolution of $0.1 \mu \mathrm{m}$. This machine is equipped whit an MQL system. The system was set to deliver the fluid at an air pressure of 33 psi $(0.23 \mathrm{MPa})$, and the cutting fluid selected was the Coolube 2210EP, manufactured by UNIST.

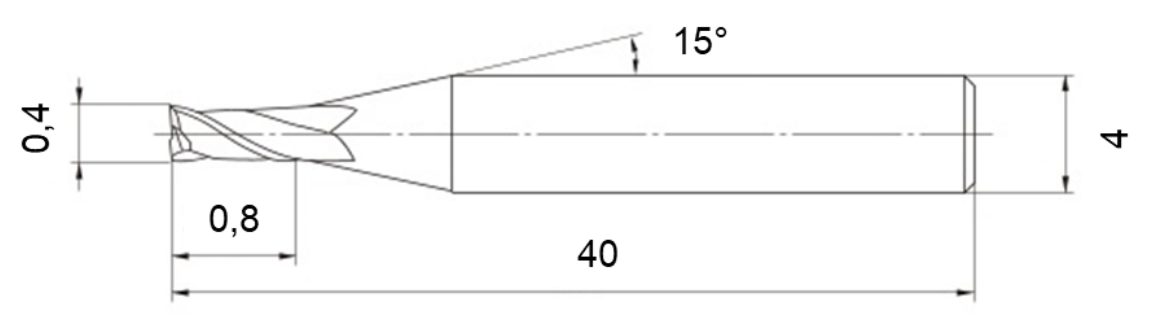

Figure 2: Micromill [18]

\subsection{Cutting Parameters}

The experiment consisted in machining micro slots of $15 \mathrm{~mm}$ in the Inconel 718. In order to continue the investigation proposed by De Oliveira et al. [13], the same cutting parameters and lubrication conditions were selected, except the cutting speed. The cutting conditions are shown in Table 3. The only different parameter from [13] is the cutting speed. This is because limitations of the dynamometer. It is important to mention that the different cutting fluid application frequency will result in different flow rates, with the first being $40.7 \mathrm{ml} / \mathrm{h}$, and the second being 270.0 $\mathrm{ml} / \mathrm{h}$, which results in 30 and 200 pulses per minute, respectively.

Table 3: Cutting Parameters

\begin{tabular}{|c|c|}
\hline Parameter & Value \\
\hline Spindle speed $\mathrm{n}(\mathrm{rpm})$ & 20000 \\
\hline Cutting speed $v_{c}(\mathrm{~m} / \mathrm{min})$ & 13.8 \\
\hline Feed per tooth $\mathrm{f}_{z}(\mu \mathrm{m} /$ tooth $)$ & 5 \\
\hline Axial depth of cut ap $(\mu \mathrm{m})$ & 40 \\
\hline & $00.0(\mathrm{dry})$ \\
\hline Cutting fluid flow rate $(\mathrm{ml} / \mathrm{h})$ & 40.7 \\
& 270.0 \\
\hline
\end{tabular}

\subsection{Outputs}

To obtain the force results, a Kistler dynamometer, model 9257b was used. This dynamometer has an operating range of $-5 \mathrm{kN}$ to $+10 \mathrm{kN}$ and can operate dynamically or almost statically [19]. Its sensitivity is adjustable, being recommended to $0.02 \mathrm{~N}$. This equipment has a low natural frequency of $3.5 \mathrm{kHz}$ [19], which limited its use for experiments with lower cutting speed since the frequency of the phenomenon of cutting is related to the number of teeth of the tool and the spindle rotation. Therefore, the cutting speed used in this work was $13.8 \mathrm{~m} / \mathrm{min}$.

After the signals were generated in the dynamometer, they passed through a Kistler 5405A distribution box, later through a Kistler conditioner / amplifier, model 504E and finally converted (analogue / digital) by a National Instruments board, NI USB-66221, with 16 bits. The signals were acquired using a LabVIEW software with a frequency of $100 \mathrm{kHz}$, to achieve an adequate trade-off between the quality of the signal and its intensity [20] Subsequently the signals were treated and analysed using the MATLAB software.

In order to verify the force measurements a computational simulation was performed using the AdvantEdge by ThirdWave Systems. This is a software dedicated to machining operations and uses an explicit dynamic, thermomechanically coupled finite element model specialized. The material properties were obtained by the software library and the tool was modelled based in SEM images and the manufacturer specifications. The tool was determined as a rigid body, with elements varying from $10.0 \mu \mathrm{m}$ to $1.0 \mu \mathrm{m}$, the workpiece material was plastically and elastically 
deformable, having initial mesh parameters as $500-10 \mu \mathrm{m}$, and as the deformations occur the adaptative mesh could generate new smaller elements, reaching $0.4 \mu \mathrm{m}$. It is important to comment that the simulation was performed considering the same cutting parameters and for dry cutting.

\section{RESULTS AND DISCUSSION}

To verify the theory presented by De Oliveira et al. [13], the cutting forces were obtained in similar conditions. This was selected once the cutting fluid is directly related to the excitations and forces of the system [21, 22]. In figure 3 is possible to observe one of the machined slots in two different regions. The left one in the red square presented worsened surface finish and adhered material in the slot surface, attributed to the lack of cutting fluid in this region during the cut.

Figure 4 contains the force signals during the cutting, for dry machining, the two different lubrication conditions and a comparison of the three lubricating atmospheres. The force was measured in the cutting direction and the negative values are the forces during cutting and the positive values are due to ploughing.

Figure 4 a shows the rough signal for dry micromachining. The cutting forces increase from about $4.6 \mathrm{~N}$ to about 8.7 $\mathrm{N}$ during the micromachining, indicating that there was a significant tool wear in the machined length $15 \mathrm{~mm}$.

When comparing the force result, Figure $4 a$ with Figure 4c, dry condition with the test with cutting fluid applied at high frequency, it is possible to observe that the initial force is similar. However, when fluid is applied at 270.0 $\mathrm{ml} / \mathrm{h}$ flow rate, there is no significant increase in the cutting force with the machined length, and the maximum force was about $6.7 \mathrm{~N}$. This different behaviour indicates that the fluid has reduced the cutting forces and, consequently, the wear rates of the micromill. Focusing on the low frequency of cutting fluid application, it is possible to notice in Figure $4 \mathrm{~b}$ that the initial value of the force is high and has peaks of force, which may be related to the lack of cutting fluid at the chip tool interface.

The results obtained are in accordance with the literature, which points out that the application of cutting fluid when machining Inconel 718 favours the process since the lubrication prevents the material from adhering to the microtool, which also results in less friction which means lower cutting forces $[23,24]$. These effects reduce the diffusion of the workpiece material to the microtool material, a common effect when machining Inconel 718 . The combined reduction of these factors helps not only in the quality of the slot, as presented in Figure 3, but in increasing the life of the micromill $[25,26]$.

As mentioned, computational simulation was performed with the intention to verify the quality of the force signals obtained experimentally. The computational results proved to be robust and the obtained results were similar to the experimental ones. In Figure 5 it is possible to observe the results of force for one single revolution of the tool, in which the micromill had not yet fully entered the part, representing the beginning of the slot. However, it is important to remark that this signal is not equivalent to the first contact because a pre-Boolean cut was used, so that the simulation started with both edges inside the part.

When considering the beginning of the micromilling, it is possible to notice that the cutting forces when the micromill is starting the slot are quite reduced. According to Wang et al. [27], for a $100 \mu \mathrm{m}$ micro-cutter, with a depth of cut of $50 \mu \mathrm{m}$, the initial forces vary from $0.2 \mathrm{~N}$ for a chip load of $0.5 \mu \mathrm{m}$ to approximately $0.8 \mathrm{~N}$ for chip load $4.0 \mu \mathrm{m}$. These results are in accordance with the ones presented here.

Regarding the application of cutting fluid, it was possible to prove quantitatively the benefits of its use for Inconel 718 micromilling operations.

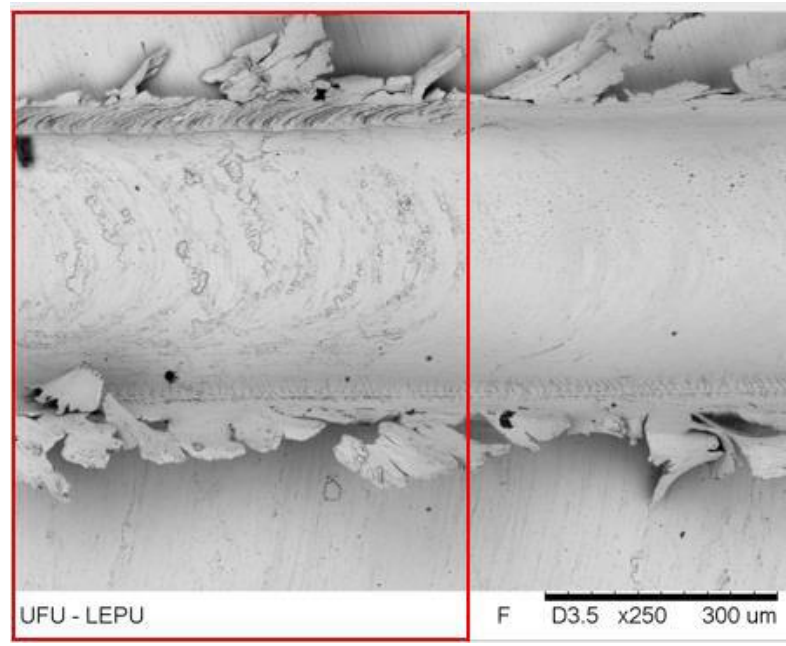

Figure 3: Micromilled slot with different surface finish due to the lack of cutting fluid [13] 


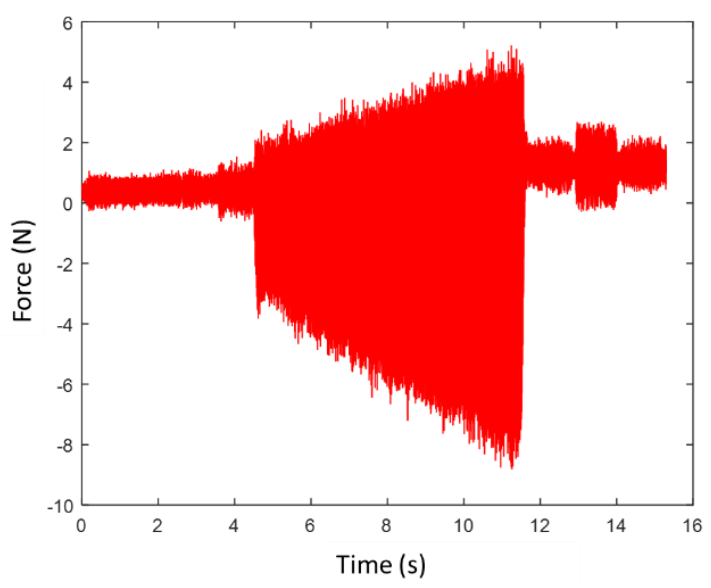

a) Force signal for dry machining

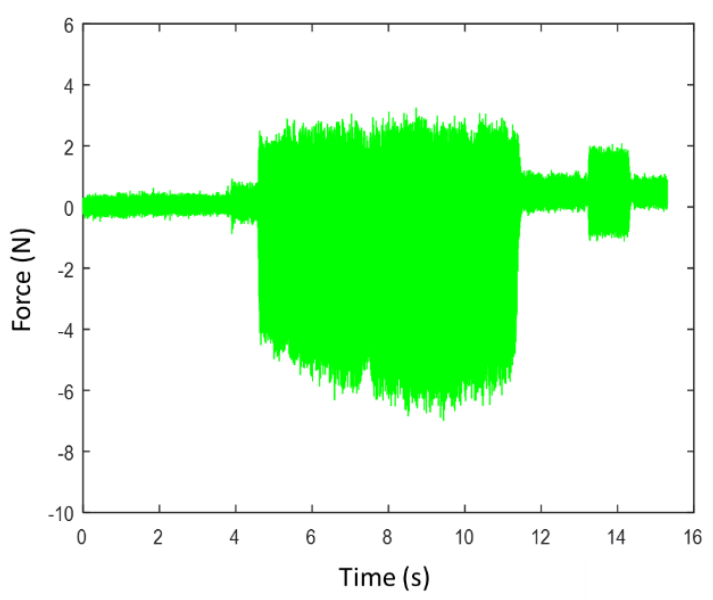

c) Force signal for machining with $270.0 \mathrm{ml} / \mathrm{h}$

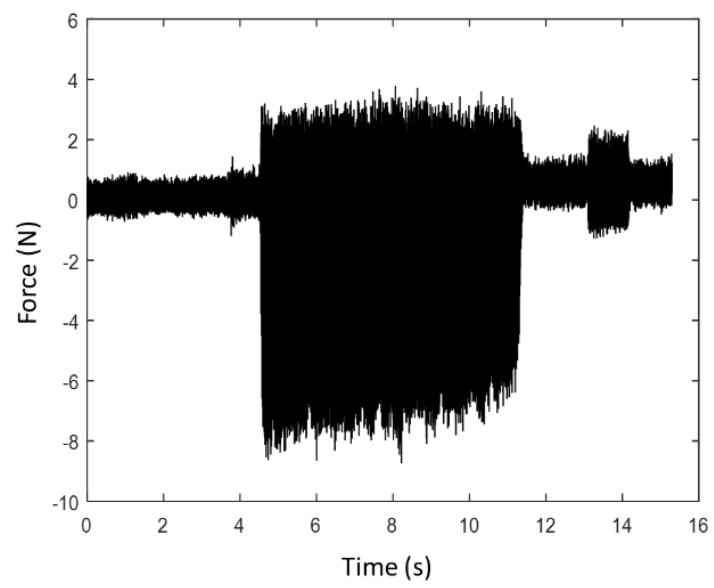

b) Force signal for machining with $40.7 \mathrm{ml} / \mathrm{h}$

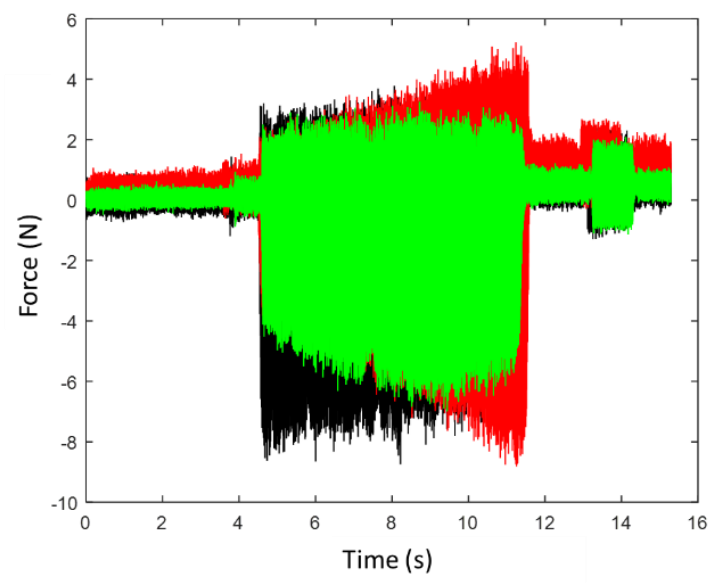

d) Comparison of forces for different atmospheres in micromilling

Figure 4: Force signals for different cooling-lubrication conditions

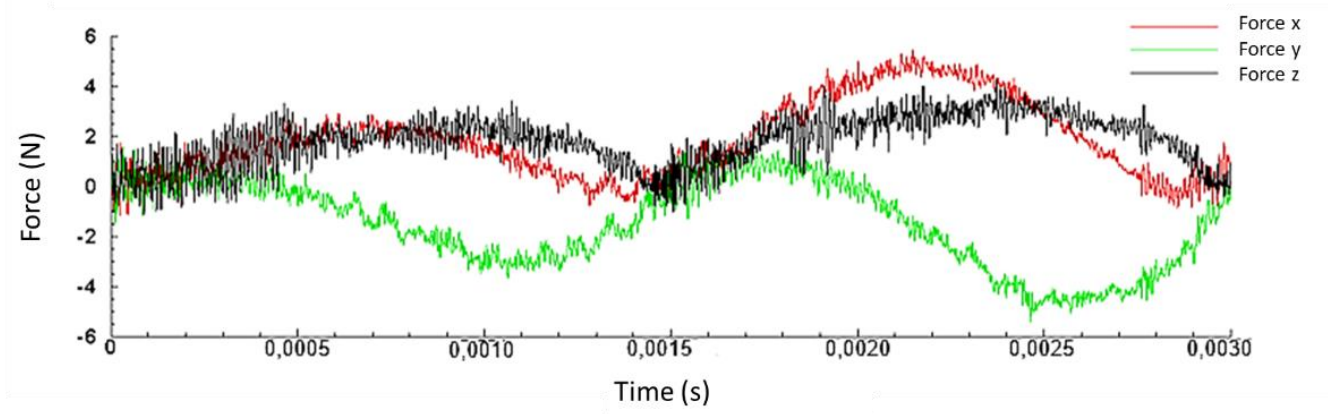

Figure 5: Computational results for cutting force. 


\section{CONCLUSIONS}

After the experimental and computational trials about micromilling Inconel 718 with a $400 \mu \mathrm{m}$ diameter cemented carbide micromill, the following conclusions can be draw:

1. The computational results presented similar results to the experimental, indicating that the cutting forces were correctly obtained.

2. The cutting force increase within one slot when dry machining, from $4.6 \mathrm{~N}$ to $8.7 \mathrm{~N}$, indicating high wear in the microtool.

3. Low frequency presented intermediate results and the presence of force pikes can be related to the absence of cutting fluid in some regions of the slot.

4. The higher flow rate resulted in the lower cutting forces with the force in the end of the slot being $6.7 \mathrm{~N}$, which near $25 \%$ of reduction when comparing to the dry cut.

\section{ACKNOWLEDGEMENT}

The authors are thankful to CAPES, CNPQ, FAPEMIC, to Faculty of Mechanical Engineering of Federal University of Uberlandia and to the Department of Mechanical Engineering, Faculty of Technology, University of Brasilia.

\section{REFERENCES}

1. Aurich, J.C., Reichenbach, I.G. \& Schuler, G.M. Manufacture and application of ultra-small micro end mills. (2012). CIRP Annals - Manufacturing Technology, 61(1), 83-86.

2. Li, W., Zhou, Z.X., Huang, X.M., He, Z. W. \& Du, Y. (2014). Development of a High-Speed and Precision MicroSpindle for Micro-Cutting. International journal of precision engineering and manufacturing, 15(11), 23752383.

3. Saha, S., Deb, S. \& Bandyopadhyay, P.P. (2020). An analytical approach to assess the variation of lubricant supply to the cutting tool during MQL assisted high speed micromilling. Journal of Materials Processing Technology, 285, 116783.

4. Saha, S., Kumar, A.S., Deb, S. \& Bandyopadhyay, P.P. (2020). An investigation on the top burr formation during Minimum Quantity Lubrication (MQL) assisted micromilling of copper. Materials Today: Proceedings, 26, 18091814.

5. Aramcharoen, A. \& Mativenga, P.T. (2009). Size effect and tool geometry in micromilling of tool steel. Precision Engineering, 33, 402-407.

6. de Oliveira, F.B., Rodrigues, A.R., Coelho, R.T. \& de Souza, A.F. (2015). Size effect and minimum chip thickness in micromilling. International Journal of Machine Tools \& Manufacture, 89, 39-54.

7. Câmara, M.A., Rubio, J.C.C., Abrão, A.M. \& Davim, J.P. (2012). State of the art on micromilling of materials, a review. Journal of Materials Science \& Technology, 28(8), 673-685.

8. Bissacco, G., Hansen, H.N. \& Chiffre,L.D. (2005). Micromilling of hardened tool steel for mould making applications. Journal of Materials Processing Technology, 167, 201-207.

9. Diniz, A.E., Marcondes, F.C \& Coppini, N.L. (2008). “Material Machining Technology", Artliber.

10. Rahman, S. M \& Liow, J. L. (2010). Modelling and Simulation of Cutting Forces in Micromachining. In Key Engineering Materials (Vol. 443, pp. 652-656). Trans Tech Publications Ltd.

11. Arif, $M \&$ Rahman, M. (2014). Fundamentals and modeling of micro-end milling operation.

12. Irani R.A., Bauer, R.J \& Warkentin, A. (2005). A review of cutting fluid application in the grinding process. International Journal of Machine Tools \& Manufacture, 45, 1696-1705.

13. De Oliveira, D., Gomes, M. C \& da Silva, M. B. (2020). Influence of cutting fluid application frequency on the surface quality of micromilled slots on Inconel 718 alloy. Procedia Manufacturing, 48, 553-558.

14. Ziberov, M., da Silva, M. B., Jackson, M., \& Hung, W. N. (2016). Effect of cutting fluid on micromilling of Ti6Al-4V titanium alloy. Procedia Manufacturing, 5, 332-347.

15. REED, R. C. The Superalloys Fundamentals and Applications. 1.ed. New York: Cambridge University Press, 2006. 392p.

16. De Oliveira, D., De Paiva, R.L., da Silva, R.B. \& Castro, P.H.C. (2020) Assessment of the grindability of Inconel 718 under different coolant delivery techniques. Journal of the Brazilian Society of Mechanical Sciences and Engineering, 42(20).

17. De oliveira,D., Gomes, M.C. \& Da Silva, M.B. (2019) Spheroidal chip in micromilling. Wear, 426-427, 16721682.

18. Mitsubishi, Mitsubishi Carbide. (2018, September). Retrieved from https://www.mitsubishicarbide.com/mmus/catalog/pdf/lj/lj403a.pdf.

19. Kistler, Multicomponent Dynamometer. (209a, July). Retrieved from https://www.kistler.com/?type $=669 \&$ fid $=95592 \&$ model $=$ document\&callee $=$ frontend.

20. Abeni, A., Lancini, M. \& Attanasio, A. (2019) Characterization of machine tools and measurement system for micromilling, Nanotechnology and Precision Engineering, 2, 23-28. 
21. Liu, D., Wang, G., Yu, J. \& Rong, Y. (2017). Molecular dynamics simulation on formation mechanism of grain boundary steps in micro-cutting of polycrystalline copper. Computational Materials Science, 126, 418-425.

22. Mittal, R.K., Kulkarni, S.S. \& SINGH, R. (2017). Effect of lubrication on machining response and dynamic instability in high-speed micromilling of Ti-6Al-4V. Journal of Manufacturing Processes, 28, 413-421.

23. Ucun, I., Aslantas, K., Bedir, F. (2013). An experimental investigation of the effect of coating material on tool wear in micro milling of Inconel 718 super alloy. Wear, 300, 8-19.

24. Zhou, I., Peng, F.Y., Yan, R., Yao, P.F., Yang, C.C. \& Li, B. (2015). Analytical modeling and experimental validation of micro end-milling cutting forces considering edge radius and material strengthening effects. International Journal of Machine Tools \& Manufacture, 97, 29-41.

25. Dudzinski, D., Devillez, A., Moufki, A., Larrouque`re, D., Zerrouki, V. \& Vigneau, J. (2004). A review of developments towards dry and high speed machining of Inconel 718 alloy. International Journal of machine tools \& manufacture. 44, 439-456.

26. Ezugwu, E. O. (2005) Key improvements in the machining of difficult-to-cut aerospace superalloys. International Journal of Machine Tools \& Manufacture, 45, 1353-1367.

27. Wang, F., Cheng, X., Liu, Y., Yang, X. \& Meng, F. (2017). Micromilling simulation for the hard-to-cut material. 13th Global Congress on Manufacturing and Management, GCMM 2016, Procedia Engineering, 174, 693-699. DOI: 10.1016/j.proeng.2017.01.209 